
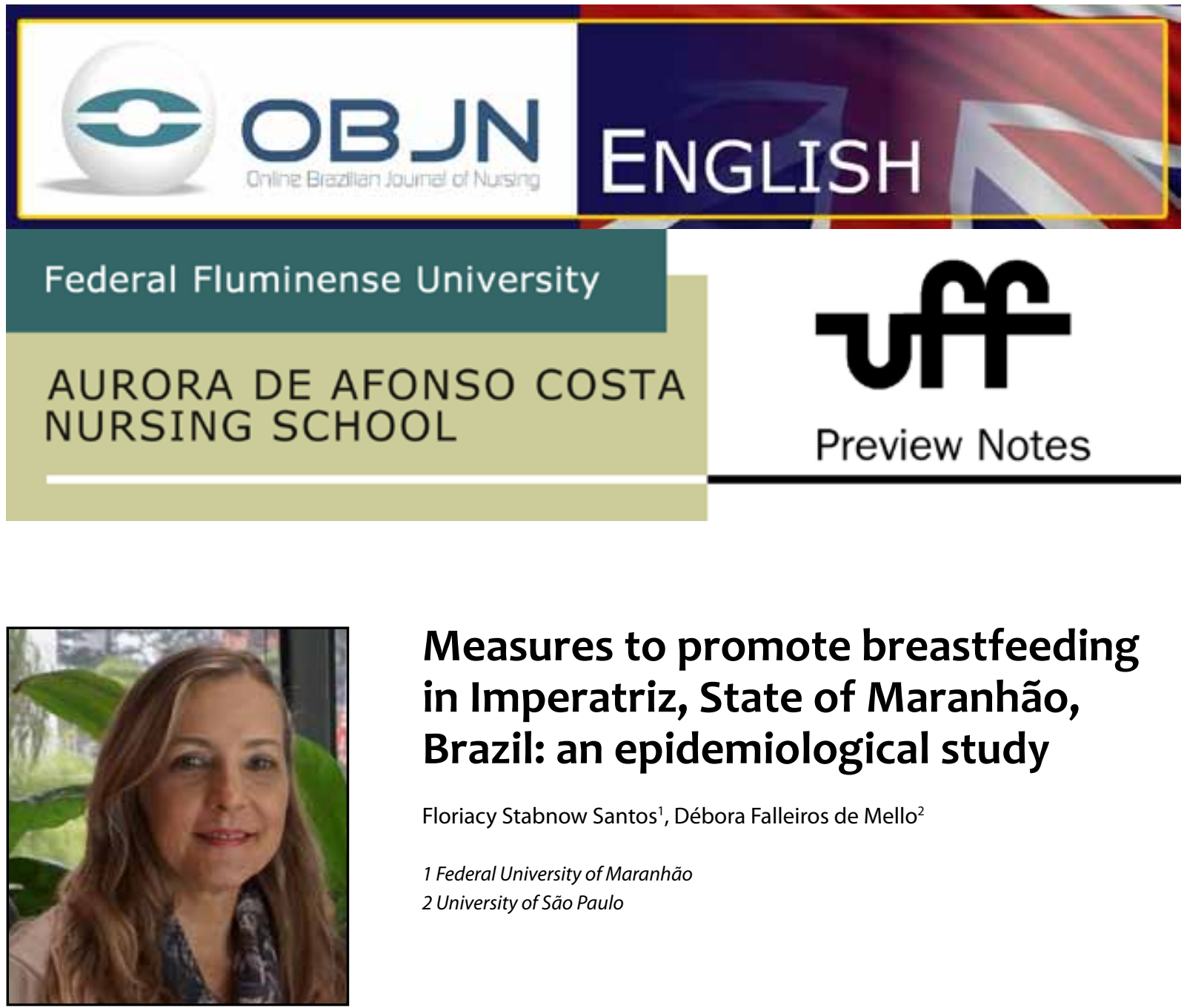

\title{
Measures to promote breastfeeding in Imperatriz, State of Maranhão, Brazil: an epidemiological study
}

\author{
Floriacy Stabnow Santos ${ }^{1}$, Débora Falleiros de Mello² \\ 1 Federal University of Maranhão \\ 2 University of São Paulo
}

\begin{abstract}
This study was part of a Ph.D. project developed in the Graduate Program in Public Health Nursing at the School of Nursing of Ribeirão Preto, University of São Paulo. Objective: We sought to analyze measures to promote breastfeeding (BF) in children under 1 year of age who were registered in the Family Health Strategy (Estratégia Saúde da Família - ESF) program in Imperatriz, State of Maranhão, with the goal of providing support for child health care. Methods: This descriptive, analytical, and cross-sectional study adopted an epidemiological approach and comprised children under 1 year of age and their mothers living in urban areas. Data were collected using semi-structured questionnaires on child feeding. Hypothesis: The implementation of measures to promote $\mathrm{BF}$ in regions covered by the ESF initiative contributes to an increased prevalence of $\mathrm{BF}$ and decreased number of cases of acute diarrhea. This project was approved by the Research Ethics Committee of the Federal University of Maranhão.
\end{abstract}

Keywords: Breastfeeding; Health Promotion; Infant. 


\section{THE PROBLEM SITUATION AND ITS SIGNIFICANCE}

The protection, promotion, and support of breastfeeding (BF) programs represent relevant strategies for the improvement of child health globally in the health sector as well as other social sectors. Moreover, early weaning is affected by several determinants that include popular myths and beliefs, poor education level, lack of preparation of health professionals, and disincentives from hospital staff. A national survey conducted in 2008 indicated that only 9.3\% of infants are exclusively breastfed until 6 months of age. ${ }^{(1)}$ The Ministry of Health (Ministério da Saúde - MS) in Brazil, in agreement with international recommendations, acknowledges that there is strong evidence that breast milk protects infants against respiratory infections and diarrhea, particularly children living in sub-optimal conditions ${ }^{(1)}$. Diarrheal diseases cause the death of 1.5 million children every year and represent the second largest cause of infant death worldwide. Therefore, the promotion of BF represents an effective intervention to improve BF rates and, consequently, reduce morbidity from infectious diseases ${ }^{(2)}$. It is also worth noting that the large extent of the Brazilian territory contributes to marked demographic and cultural differences, in addition to differences in habits and health status. In the context of diarrheal diseases, situations of socioeconomic vulnerability can be directly linked to increased exposure to such diseases, particularly starting at the age of 3 months, due to the early introduction of solid foods in the diet of infants and their increased exposure to environmental pathogens. Therefore, further investigation of this scenario is crucial to improve the understanding of diarrheal diseases in infancy ${ }^{(3)}$. In addition, it is particularly important that public health policies aimed at promoting, protecting, and supporting
BF programs are created and implemented, with the aim of reducing the incidence of childhood illnesses, including diarrhea.

\section{HYPOTHESIS}

The implementation of measures to promote $B F$ in regions with ESF coverage contributes to an increased prevalence of BF and a decreased number of reports of acute diarrhea in the municipality of Imperatriz, State of Maranhão.

\section{OBJECTIVES}

- Analyze the measures recommended by the MS to promote BF in children under 1 year of age who were registered in the health units of the ESF program in Imperatriz;

- Identify the prevalence of each type of BF (exclusive, partial, complemented, and mixed);

- Identify cases of acute diarrhea reported in children up to 4,6 , and 12 months of age in the regions covered by the ESF program;

- Correlate BF indicators and the reports of acute diarrhea in children under 1 year of age with the measures used to promote BF.

\section{METHODS}

This descriptive, analytical, cross-sectional, and quantitative study adopted an epidemiological approach and was conducted between 2013 and 2014. We sought to analyze the association between $\mathrm{BF}$ indicators and the reported cases of acute diarrhea in children. Children under 1 year of age who were previously registered in the ESF program and who lived in urban areas in the municipality of Imperatriz were eligible to participate in the study. The exclusion criteria 
were as follows: children from premature births, those with a diagnosis of diarrhea-causing diseases, twins, and children born to mothers who had mental or infectious diseases such as HIV/ AIDS. The study population comprised children under 1 year of age and their mothers. In May 2012, 2,333 children had been registered in the ESF program, according to data from the Primary Care Information System (Sistema de Informação da Atenção Básica - SIAB). Considering a confidence interval of $95 \%$, the sample size comprised 341 children. To account for possible losses to follow-up or dropouts, a surplus percentage of $33.5 \%$ was added, so that the total sample included 456 children. Data were collected using a semi-structured questionnaire on child feeding and other issues related to the occurrence of diarrhea and hospitalization. For construction of the database, Excel for Windows will be used, and SPSS software version 17.0 will be used for statistical analysis. Data analysis will be performed based on descriptive and analytical statistics, with tabulation of the measures of central tendency and variability for socioeconomic, demographic, prenatal care, and birth variables. In addition, the analysis will take into account the profiles of the newborns and the diseases that occurred during the first year of life.

\section{REFERENCES}

1. Ministério da Saúde (Brasil). Pesquisa de prevalência de aleitamento materno em municípios brasileiros. Brasília: Ministério da Saúde; 2010.

2. World Health Organization (USA). Diarrhea: why children are still dying and what can be performed: UNICEF and WHO launch report on the second greatest killer of children. 2009 [cited 2014 March 6]. Available from: http://www.unicef.org/ media/media_51407.html

3. Barreto MS, Silva RLDT, Marcon SS. Morbidity in children less than one year of age in risky con- ditions: a prospective study. Online Braz J Nurs [Internet]. 2013 [cited 2013 September 29]; 12 (1): 5-18. Available from: http://www.objnursing.uff. br/index.php/nursing/article/view/3999

AUTHOR CONTRIBUTIONS

- Floriacy Stabnow Santos: Conception and design, writing, and final approval of the manuscript.

- Débora Falleiros de Mello: Conception and design, critical review, and final approval of the manuscript.

\section{PROJECT INFORMATION}

This study was part of a Ph.D. project developed as part of the Graduate Program in Public Health Nursing, School of Nursing of Ribeirão Preto, University of São Paulo. The Ph.D. student passed the Qualifying Exam on 03/05/2013.

All authors participated in the phases of this publication in one or more of the following steps, in According to the recommendations of the International Committee of Medical Journal Editors (ICMJE, 2013): (a) substantial involvement in the planning or preparation of the manuscript or in the collection, analysis or interpretation of data; (b) preparation of the manuscript or conducting critical revision of intellectual content; (c) approval of the versión submitted of this manuscript. All authors declare for the appropriate purposes that the responsibilities related to all aspects of the manuscript submitted to OBJN are yours. They ensure that issues related to the accuracy or integrity of any part of the article were properly investigated and resolved. Therefore, they exempt the OBJN of any participation whatsoever in any imbroglios concerning the content under consideration. All authors declare that they have no conflict of interest of financial or personal nature concerning this manuscript which may influence the writing and/or interpretation of the findings. This statement has been digitally signed by all authors as recommended by the ICMJE, whose model is available in http://www. objnursing.uff.br/normas/DUDE_eng_13-06-2013.pdf

Received: 09/24/2013

Revised: 02/27/2014

Approved: 02/28/2014 